
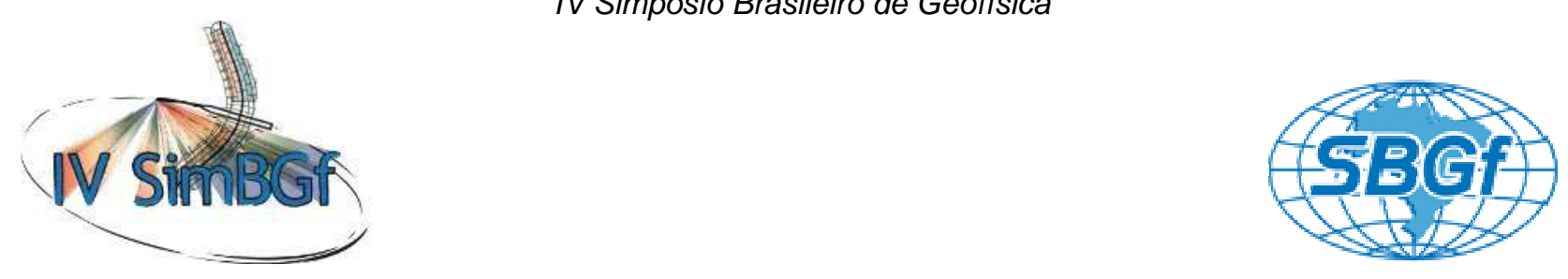

\title{
Análise Morfotectônica do Alto de Cabo Frio e sua Influência na Formação e Desenvolvimento das Bacias de Campos e Santos.
}

Rodolfo Marques da Silva - Aluno de Pós-Graduação em Geologia e Geofísica Marinha - LAGEMAR / UFF,

Eliane da Costa Alves - Departamento de Geologia, LAGEMAR - UFF,

Vitor Sá de Albuquerque - Aluno de Graduação em Geofísica - UFF,

Patrícia Pitta Pinheiro de Souza Melgaço - Aluna de Graduação em Geofísica - UFF,

Leandro Gonçalves Machado - Aluno de Pós-Graduação em Geologia e Geofísica Marinha - LAGEMAR / UFF,

Camilo Iván Ordoñez Aristizábal - Aluno de Pós-Graduação em Geologia e Geofísica Marinha - LAGEMAR / UFF.

Copyright 2010, SBGf - Sociedade Brasileira de Geofísica

Este texto foi preparado para a apresentação no IV Simpósio Brasileiro de Geofísica, Brasília, 14 a 17 de novembro de 2010. Seu conteúdo foi revisado pelo Comitế Técnico do IV SimBGf, mas não necessariamente representa a opinião da SBGf ou de seus associados. É proibida a reprodução total ou parcial deste material para propósitos comerciais sem prévia autorização da SBGt.

\section{Abstract}

This paper presents a study in respect of the Cabo Frio High, a tectonic-structural feature located in the southeastern Brazilian continental shelf that segments the Campos and Santos basins. During the development of this project were interpreted data from 2D multichannel seismic calibrated with vertical wells beyond airborne potential methods. From this analysis, it was possible to infer that this high is from magmatic nature and that it acted as a sedimentary barrier between the Campos and Santos basins until the Lower Aptian, i.e., during the rift phase. Afterwards, this function became restricted to the higher areas formed by volcanic cones inside the Cabo Frio's High area.

\section{Introdução}

A margem continental do Sudeste do Brasil vem sendo o alvo de intensos estudos evolutivos desde meados dos anos 70, com o descobrimento de recursos petrolíferos na bacia de Campos. Com as constantes descobertas de campos gigantes de petróleo principalmente nas regiões das bacias de Campos e Santos esta é até hoje uma das regiões mais pesquisadas em todo o planeta. Delimitando a região entre estas bacias encontra-se o Alto de Cabo Frio, porção elevada do embasamento localizada entre as latitudes $22,5^{\circ}$ e $23,5^{\circ} \mathrm{S}$, de direção NW-SE. O A Ito está inserindo na região da margem continental onde acontece a inflexão na direção da linha de costa e da plataforma continental, passando de E-W na Bacia de Santos, para NE-SW na Bacia de Campos. O presente trabalho visa localizar geograficamente o Alto de Cabo Frio, caracterizar a sua constituição litológica e estimar até quando este atuou como barreira topográfica para a sedimentação entre as bacias de Campos e Santos. Para a realização deste trabalho foram utilizados dados de sísmica 2D multicanal, poços verticais além de aerolevantamentos gravimétricos e magnetométricos.

\section{Metodologia}

Para a realização deste trabalho foi utilizada uma ampla gama de dados de sísmica 2D multicanal (dezenas de linhas sísmicas com espaçamento variável e profundidade de penetração alcançando até aproximadamente 8 segundos), poços verticais (amostragem e perfis geofísicos) (Fig. 1), além de dados gravimétricos e magnetométricos aerolevantados (Figs. 4 e 5). Todas estas informações foram analisadas tendo como enfoque a região à costa do Estado do Rio de Janeiro bordejante ao Alto de Cabo Frio. Para a interpretação das linhas sísmicas foi utilizado o software SMT Kingdom.

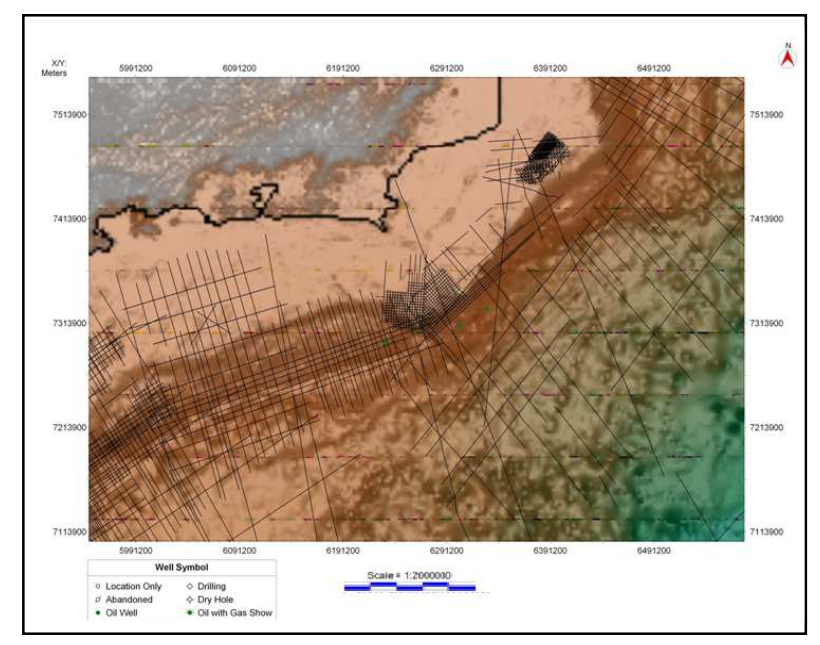

Fig.1. Mapa Batimétrico da Margem Sudeste Brasileira evidenciando a base de dados disponível para análise sísmica.

A interpretação dos dados sísmicos foi desenvolvida baseando-se em conceitos de sismoestratigrafia (Mitchum \& Vail, 1977), considerando-se a geometria interna e externa das camadas, as continuidades e o 
caráter acústico dos refletores além das técnicas de Brown (1993), mais adequadas a trabalhos de caráter estrutural. Seguindo essas propostas foi realizada a identificação dos horizontes nos dados de poços, o reconhecimento das principais falhas em seções sísmicas, o controle inicial dos horizontes usando seções dip e strike, a revisão dos horizontes e falhas, mapas estruturais em tempo e mapas de isópacas.

A influência efetiva do Alto de Cabo Frio na sedimentação das bacias de Campos e Santos pode ser observada em caráter regional e local a partir dos mapas de isópacas da Sequência Rifte e da Sequência Marinha Regressiva (Figs. 4 e 5). Estes foram gerados a partir de análises geoestatísticos de gridagem dos horizontes mapeados na interpretação sísmica utilizando-se o software ArcGis. Para o processamento dos dados potenciais foi usado o software Geosoft Oasis Montaj.

Uma importante contribuição para a interpretação geofísica do embasamento na região do Alto de Cabo Frio foi prestada pela análise de mapas de métodos potenciais (Figs. 6 e 7). Estes foram fundamentais na determinação da natureza litológica do Alto devido a identificação de anomalias de densidade positiva e susceptibilidade magnética na mesma região onde a sísmica havia revelado uma elevação do embasamento.

\section{Resultados}

Uma das premissas deste trabalho foi a visualização das seções tendo como foco a busca de feições que caracterizassem a elevação do embasamento à margem da região de Cabo Frio - RJ. A partir disso, foram alcançadas algumas conclusões que atribuem novos conceitos sobre a localização e o tempo de atuação do Alto de Cabo Frio como barreira sedimentar entre as bacias de Campos e Santos.

O projeto baseou-se em um intenso trabalho de interpretação sísmica onde foram analisadas dezenas de linhas cruzando a margem costeira do Estado do Rio de Janeiro. Deste modo, foi possível visualizar uma grande área formada por um patamar, anomalamente soerguido em relação às suas vizinhanças, sobre a região fronteiriça entre as bacias de Campos e Santos. Prosseguindo-se o desenvolvimento da análise de dados sísmicos, corroborado pela análise de métodos potencias, foi possível propor uma tentativa de localização geográfica efetiva para o Alto de Cabo Frio (Fig. 2). No interior da área demarcada pelo mesmo, observa-se uma região cuja altitude é ainda mais elevada que o restante e sua caracterização fisiográfica descreve estruturas semelhantes a edificações vulcânicos (Fig. 3).

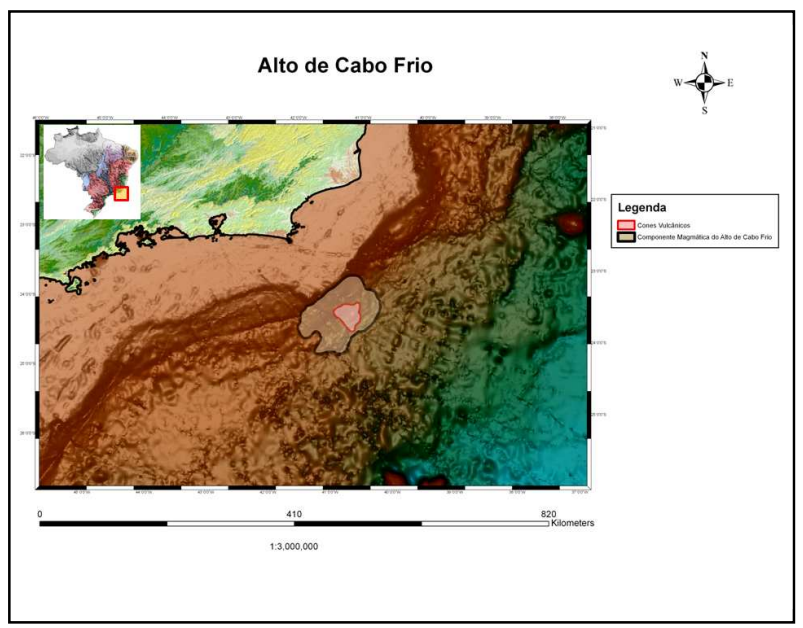

Fig. 2. Mapa Batimétrico da Margem Sudeste Brasileira destacando a localização do Alto de Cabo Frio

A análise sísmica integrada aos dados extraídos do registro geológico de poços e de informações bibliográficas propiciou a determinação de sete domínios cronoestratigráficos baseados em discordâncias e superfícies de inundação, são eles: Embasamento (Neocomiano), Base do Sal (Barrremiano - Eo-Aptiano), Topo do Sal (Aptiano), Albiano (carbonatos), Paleoceno Eoceno (vulcânicas), Oligoceno e Mioceno (Fig. 3).

O Alto de Cabo Frio está caracterizado como uma elevação do embasamento, de natureza magmática, onde estão associados picos cuja estruturação fisiográfica cuneiforme assemelha-se a montes vulcânicos. Conforme pôde ser constatado, sua estrutura funcionou como barreira topográfica para a sedimentação entre Campos e Santos desde o Neocomiano até o EoAptiano. A região onde se registram feições de cones vulcânicos apresenta-se como uma barreira topográfica local de sedimentação entre estas bacias, dado o grande desnível altimétrico observado entre esta área e suas vizinhanças.

A linha sísmica dip 0239-0364 está localizada no extremo norte da bacia de Santos (Fig. 3). Seu embasamento é caracterizado por um platô anômalo cuja profundidade aumenta em direção a sudeste. Esta elevação se inicia logo após a quebra da linha de charneira Cretácea, com a formação uma marcante calha de ruptura. Também é notável nesta seção a ocorrência de um grande cone vulcânico ao centro da área demarcada como Alto de Cabo Frio. Observando-se detalhadamente este cone pode-se inferir que esta área tenha sofrido uma evolução marcada por reativações tectônicas. Tal afirmação é proposta devido às terminações dos refletores em ambos os lados do pico serem apresentadas na forma de acunhamentos (pinch outs) e, na maioria dos casos, as camadas sedimentares tendem a truncar com os plugs magmáticos formando feições de onlap. Esta feição sugere um processo de soerguimento posterior à deposição dos sedimentos que exibem esta característica. Em outras palavras, estes foram 
deformados pelo movimento ascendente do pico magmático. Com isso, pode-se concluir que o pico atuou como uma barreira deposicional local até períodos bastante recentes do Neógeno. Além disso, a existência de derrames de vulcânicas do Paleógeno (PaleocenoEoceno) associadas às paredes do cone indica que o mesmo possa ter atuado como um condutor de material mantélico. Estes extravasamentos magmáticos são classificados como sequências vulcano-sedimentares de idade Paleoceno Inferior a Eoceno (40 - $50 \mathrm{Ma}$, Mizusaki \& Mohriak, 1993) onde derrames basálticos se intercalam com outras rochas vulcânicas e sedimentares (Mohriak et al. 1989 e 1990).

A charneira Cretácea é uma feição do embasamento formada pela subsidência tectônica associada ao afinamento crustal que desencadeia o flexuramento da margem continental (Fig.3). A partir da análise sísmica pode-se observar que esta estrutura esteve exposta até o Oligoceno Inferior, visto que a superfície que a sobrepõe corresponde à discordância caracterizada como Marco Azul. Na região das bacias de Campos e Santos o trend deste lineamento apresenta uma notável inflexão de NESW para E-W, acompanhando a mesma direção da linha de costa. Esta curvatura, também observada na batimetria e na estruturação da margem e do bordo continental adjacentes, foi associada por Alves (2002) à Zona de Transferência do Rio de Janeiro e à Zona de Fratura de Martim Vaz.

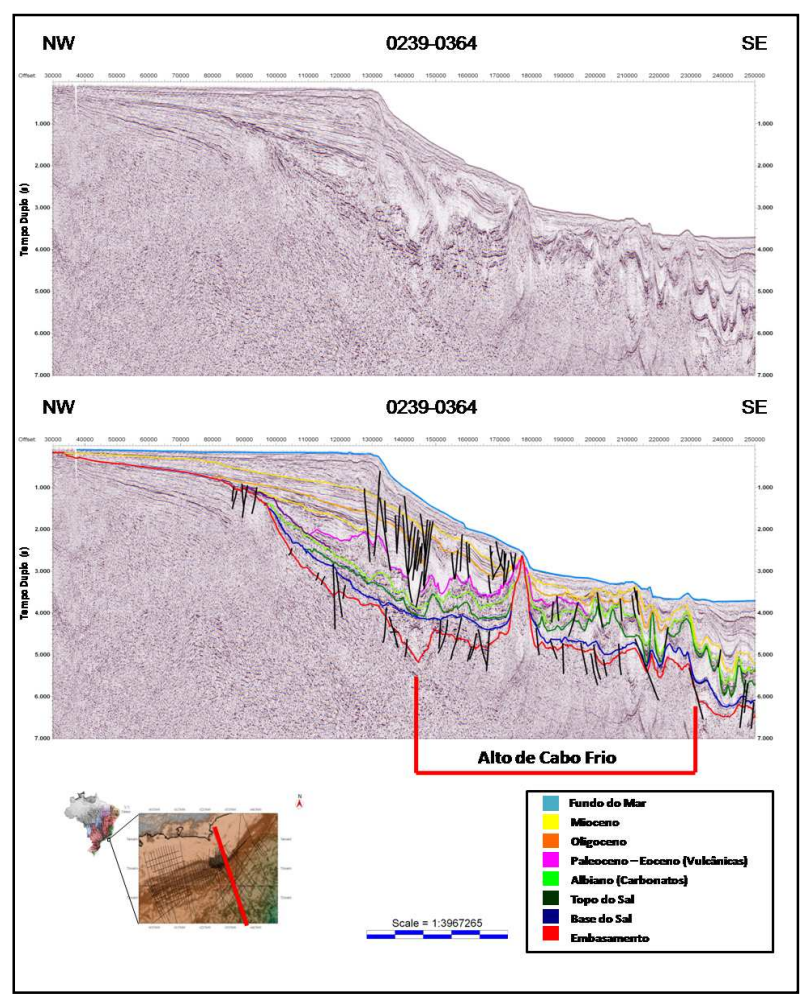

Fig. 3. Linha sísmica dip caracterizando morfologicamente a região do Alto de Cabo Frio e a destacando a existência de um grande cone vulcânico sobre sua superfície.
O Mapa de Isópaca da Sequência Rifte representa a espessura sedimentar depositada desde o Neocomiano até o Eo-Aptiano (Fig. 4). A partir do mesmo pode-se visualizar que nas áreas a nordeste e sudoeste do Alto de Cabo Frio as espessuras de sedimentos depositados são claramente superiores às que se encontram no seu interior. Além disso, a área onde se situam os plugs magmáticos apresenta notável desnível altimétrico superior em relação ao restante da área mapeada.

O Mapa de Isópaca da Sequência Marinha Regressiva descreve a espessura de sedimentos assentados durante período que se estende desde o Cenomaniano até 0 Holoceno (Fig. 5). Tendo em vista as informações obtidas por este mapa conclui-se que, durante o mesmo período, a Componente Magmática do Alto de Cabo Frio encontrava-se totalmente recoberta e, por isso, não exerceu nenhuma influência regional na sedimentação entre as bacias de Campos e Santos. Entretanto, conforme fora visualizado na interpretação sísmica existem locais isolados onde as elevações formadas pelos cones vulcânicos propiciaram uma barreira local para a livre circulação sedimentar entre Campos e Santos (Fig. 3).

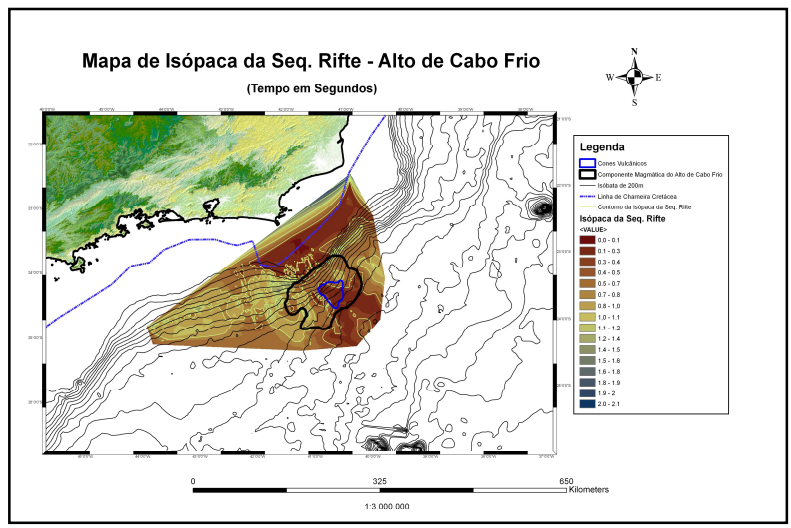

Fig. 4. Mapa de Isópaca da Sequência Rifte (Embasamento - Base do Sal).

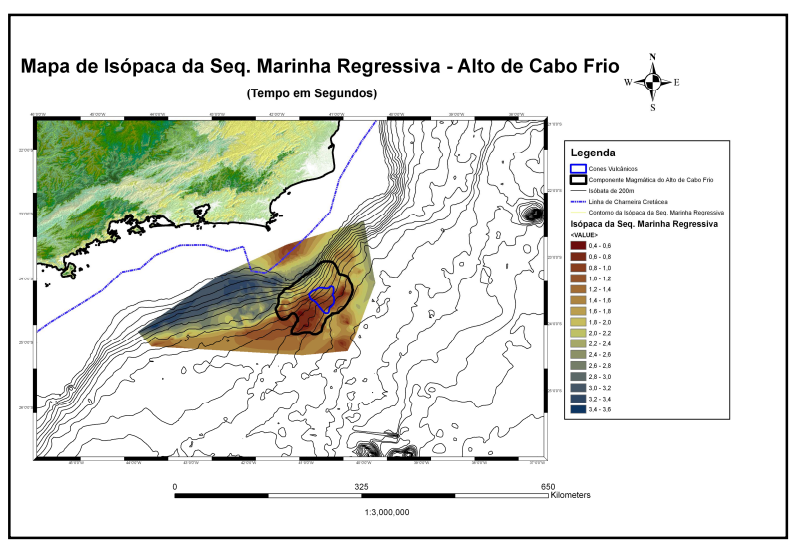

Fig. 5. Mapa de Isópaca da Sequência Marinha Regressiva (Topo do Albiano - Fundo do Mar). 
Os dados de métodos potenciais utilizados neste trabalho são derivados do processamento, análise e interpretação de dados aerolevantados obtidos através de uma licença adquirida pelo Laboratório de Geologia Marinha (LAGEMAR - UFF) junto ao Grupo GETECH. Com base nestes dados, foram gerados o mapa gravimétrico de Anomalia Isostática (Fig. 6) e o mapa magnético de Sinal Analítico do Campo Total (Fig. 7).

O Mapa processado de forma a evidenciar resposta gravimétrica da região do Alto de Cabo Frio baseando-se nas anomalias isostáticas permitiu uma considerável caracterização estrutural desta região (Fig. 6). Nele podese observar que a área onde está localizado o Alto de Cabo Frio está contida em uma porção onde as densidades são maiores do que em suas adjacências. Isto pode indicar a hipótese de um soerguimento tectônico. Nota-se também que a região onde se encontram os picos vulcânicos mostra densidades ainda maiores. Observando-se mapa em seu contexto regional pode-se inferir uma estrutura complexa de densidade bastante elevada com direção NE-SW infletindo para NNE-SSW à costa da porção norte do Estado do Rio de Janeiro. Esta apresenta uma extensão que se projeta desde a zona de charneira Cretácea até uma distância de aproximadamente $160 \mathrm{~km}$ da linha de costa.

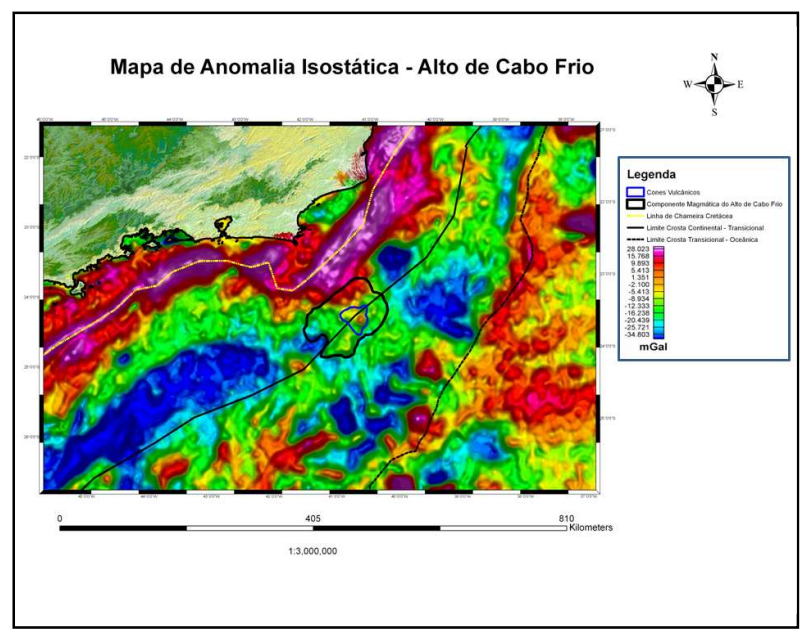

Fig. 6. Mapa evidenciando a resposta gravimétrica do Alto de Cabo Frio pela Anomalia Isostática.

Analisando-se os dados do Mapa de Sinal Analítico do Campo Magnético Total é possível visualizar uma eminente anomalia de susceptibilidade magnética exatamente na região onde foi definida a Componente magmática do Alto de Cabo Frio (Fig. 7). Esta pode estar relacionada aos eventos magmáticos e seus respectivos dutos vulcânicos em virtude da natureza circular das ilhas magnéticas e das freqüentes estruturas interpretadas na sísmica como cones vulcânicos (Fig. 2).

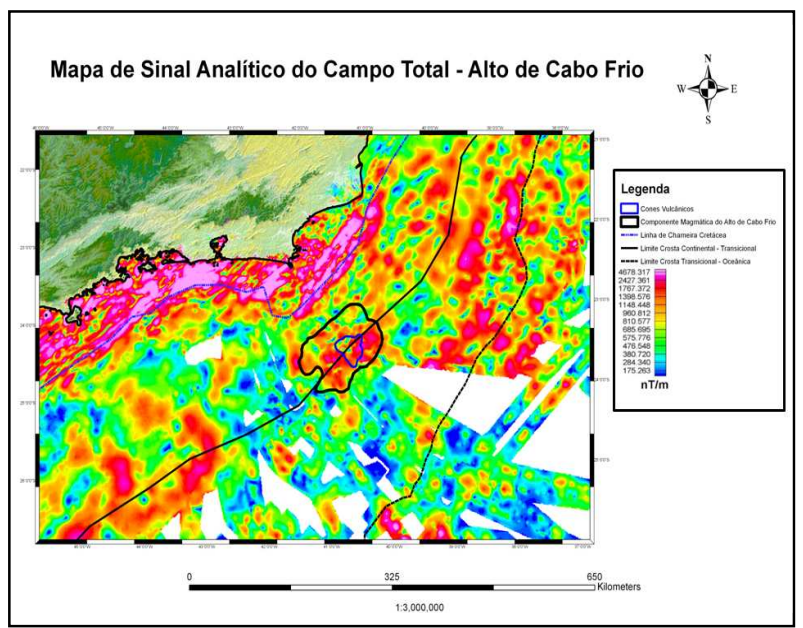

Fig. 7. Mapa Magnetométrico de Sinal Analítico do Campo Total evidenciando uma vasta anomalia de susceptibilidade magnética na região do Alto de Cabo Frio.

\section{Conclusões}

A partir da análise morfotectônica e estratigráfica do Alto de Cabo Frio pode-se concluir que este atuou como barreira sedimentar entre as bacias de campos e Santos até o final da fase rifte (Eo-Aptiano). Conforme pode ser visualizado pela sísmica, feições estruturais interpretadas como cones vulcânicos influenciaram localmente a deposição sedimentar até períodos bem mais recentes. Mediante a análise de dados sísmicos é possível concluir que o Alto de Cabo Frio é uma feição do embasamento vulcânico e, por isso, procede pelo menos desde o Neocomiano.

O emprego de métodos potenciais mostrou-se uma ferramenta muito eficiente para complementar a sísmica no estudo de grandes feições geológicas. A partir do emprego conjunto de ambos os métodos sísmico, gravimétrico e eletromagnético foi possível a discriminar delimitação geográfica efetiva do Alto de Cabo Frio e da porção do embasamento caracterizada como cones vulcânicos.

Com base nas estruturas observadas pela análise sísmica e nos dados do Mapa Magnético de Sinal Analítico do Campo Total pode-se confirmar que a região delimitada como Alto de Cabo Frio é composta por rochas de natureza magmática (Fig. 7). Esta constatação é evidenciada pelos altos valores de susceptibilidade magnética observados em seu interior e pela natureza circular observada nas ilhas magnéticas posicionadas no interior do Alto, típicas de rochas máficas.

Contudo, tais informações ainda necessitam de mais pesquisas e um nível de detalhamento maior, para que os argumentos possam ser defendidos com maior propriedade e, assim, dirimir as possíveis controvérsias. 


\section{Agradecimentos}

Os autores registram profundos agradecimentos ao Departamento de Geologia da universidade Federal Fluminense (LAGEMAR - UFF) pela cessão dos dados e à companhia operadora de petróleo e gás REPSOL pelo apoio financeiro e também pelos comentários e sugestões que muito contribuíram para o desenvolvimento deste projeto.

\section{Referências}

Alves, E. C. da - 2002 - Zonas de fraturas Oceânicas e suas relações com compartimentação tectônica do Sudeste do Brasil. Universidade Federal do Rio de Janeiro (Tese de Doutorado), p(85-109), 2002.

Brown, A. R. Interpretation of 3-D Seismic Data. AAPG Memoir, 42, 3th edition, 341p., 1993.

Mitchum, R.M.Jr \& Vail, P. R. - 1977 - Seismic stratrigraphy and global changes of sea-level, part 1 and 2: The depositional sequence as a basic unit for stratigrphic analysis. In: Payton, E.E., (Ed.), Seismic stratigraphy application to hydrocarbon exploration. Tulsa, American Association Petroleum Geologists Memoir 26, $\mathrm{p}$ (53-62), 1977.

Mizusaki, A. M. \& Mohriak, W. U. - 1993 - Sequências vulcano-sedimentares na região da plataforma continental de Cabo Frio. RJ - Simp. Geol. Sudeste 3, Rio de janeiro. Atlas RJ. SBG/NRJ -SP, p(52-56), 1993.

Mohriak, W. U.; Barros, A. Z.; Fujita, A. M. - 1989 Geologia da Plataforma continental de Cabo Frio, RJ.. In: SIMP. GEOL. SUDESTE, 1, Rio de Janeiro, 1989. Resumos Rio de Janeiro, SBG, p(21), 1989.

Mohriak, U. W. \& Barros, A. Z. N. de - 1990 - Novas Evidências de Tectonismo Cenozóico na Região Sudeste do Brasil: O Gráben de Barra de São João na Plataforma de Cabo Frio, RJ, p(187-191), 1990. 